\title{
CORPOÉTICO: A PALAVRA EM POTLACH
}

POETHICALBODY: THE WORD IN POTLACH

\author{
Adriana Carolina Hipolito de Assis \\ Doutoranda em Literatura pela Universidade Federal de Santa Catarina \\ Mestre em Literatura e Crítica Literária pela Pontifícia Universidade Católica de São Paulo \\ Bolsista da CAPES \\ E-mail: adricarolbas@gmail.com
}

\begin{abstract}
Marcos José Müller
Doutor em Filosofia pela Universidade Federal do Rio de Janeiro

Mestre em Filosofia pela Universidade Federal do Rio Grande do Sul

Professor associado da Universidade Federal de Santa Catarina

E-mail: mjmuller@cfh.ufsc.br
\end{abstract}

\section{RESUMO}

O presente trabalho tem por objetivo pôr em debate o conceito de potlach a partir das obras Claude Lévi-Strauss o el Nuevo Festín de Esopo de Octávio Paz e A Parte Maldita de Georges Bataille. Potlach é uma definição utilizada pela antropologia e está presente, principalmente, na obra Ensaio sobre a Dadiva, de Marcel Mauss, texto que observa as relações de troca nas sociedades primitivas e explica a relação de dispêndio erotizado na poética. O presente trabalho pretende compreender, a partir dessa discussão, o corpo poético erotizado latino como um potlach.

Palavras-chave: Corpo. Potlach. Octávio Paz. Georges Bataille.

\section{ABSTRACT}

This work aims to bring into discussion the concept of potlach from the works Claude Lévi-Strauss o el Nuevo Festín de Esopo, by Octavio Paz and A Parte Maldita, by Georges Bataille. Potlach is a definition used by anthropology and is it present mainly in the work Ensaio sobre a Dádiva, by Marcel Mauss. It is a text that observes the exchange relations in primitive societies and explain the eroticized expenditure relations in poetics. This study aims to understand, from this discussion, the eroticized Latin poetic body as a potlach.

Keywords: Body. Potlach. Octavio Paz. Georges Bataille. 


\section{O OLHAR DE PAZ SOBRE O POTLACH NO FESTIM DE LÉVI-STRAUSS.}

Quase toda ensaística de Octavio Paz tem por discussão a palavra erotizada. As entradas para compreensão dessa estética são abrangentes e a fortuna crítica extensa. É sabido que Paz, além de poeta e crítico, foi embaixador do México e isso possibilitou, como aponta Celso Lafer (MACIEL, 1999; PAZ, 1990), pensar a poesia num contexto "particular" - mexicano e/ou latino e "universal" - pertencente ao mundo -. Logo, refletir sobre questões estéticas, políticas e economias com ética era uma forma de meditar sobre o erotismo e, consequentemente, sobre como a arte e a literatura se manifestam. A obra Claude Lévi-Strauss o el Nuevo Festín de Esopo (1972), escrita no final da década de 1960, traz como discussão inicial a paixão de Octávio Paz pela antropologia e sua inquietação acerca das interdições (tabu e incesto), aspectos que o fizeram buscar, nas teorias do antropólogo Claude Lévi-Strauss, respostas para a compreensão do erotismo dentro de um sistema de signos. Ocorre que essa questão, a nosso ver, é apenas pano de fundo para refutar a noção de dispêndio presente na obra de Georges Bataille, A Parte Maldita (2013). Essa diferença de olhar para obra de Georges Bataille demonstra, nas entrelinhas da discussão de Paz, um problema de fonte em Bataille no que concerne à interpretação teórica de Marcel Mauss acerca do potlach $^{l}$, na medida em que se fixa em um único tipo de potlach relacionado à morte e ao excesso e, além disso, demarca o terreno para um tipo de dispêndio e de estética essencialmente latina.

A paisagem e a sinfonia de Claude Lévi-Strauss encantaram Paz, principalmente por constituir-se como um "quebra-cabeça" que se autotraduz enquanto fenômeno. Sua estrutura determina o sentido ou a significação dos vários signos e símbolos traçados num ambiente. Daí o diálogo constante do poeta mexicano com o pensamento selvagem que lhe possibilitou construir associações como, por exemplo, a do poeta como mago ou xamã da palavra, capaz de sensorializar, captar signos que dificilmente um "civilizado" conseguiria, mas que, com o tempo, deixa os instintos para pensar a palavra ou a arte com técnica. Importa para a discussão de Paz, leitor de Lévi-Strauss, a compreensão do homem inserido na natureza e a sistematização de sua linguagem na relação com as interdições. A estrutura das partes explica o todo na circulação dos fenômenos sociais, linguísticos, estéticos, religiosos e jurídicos. Cada parte da linguagem ou unidade mínima de significação - texto, oração, palavra, morfema, fonema - é um feixe de relações sistematizado desde o plano fonológico para explicar a natureza opositiva e binária do signo em sua estrutura. O som e o sentido constroem significação na relação com outro fonema, daí a distinção como em pata e bata ou em sim e nãa. Assim como os fonemas, os termos de parentesco 
são elementos de significação. A repetição de sons ou de regras de matrimônio é socialmente visível e, por outro lado, produto de leis gerais invisíveis ao homem, isto é, parte dessa estrutura é inconsciente, embora seja racional: "hablamos sin saber que, cada vez que lo hacemos, ponemos en movimiento una estrutura fonológica" (PAZ, 1972, p. 17). Ocorrendo o mesmo nas relações de parentesco constituídas socialmente, o que se pressupõe a partir da antropologia é que somos todos determinados desde a constituição da linguagem. Essa circulação de signos e de regras sociais constitui parte das inquietações de Paz, uma vez que o nexo do sentido deriva de uma convenção arbitrária que também comparece nas relações de interdição, logo, o sistema se dá por analogia com os signos (arte, ritos, economia, religião etc.), tal como explicita Paz acerca dos estudos filosóficos do pragmático Charles S. Peirce, que afirma que: "el sentido de símbolo es su traducción en otro símbolo" (PAZ, 1972, p. 19). Embora Paz não tenha feito nenhum estudo aprofundado das teorias de Peirce, essa tradução de signo para signo explicitada por ele é, na realidade, um "representamen" ou "aquilo que, sob certo aspecto ou modo, representa algo para alguém. Dirige-se a alguém, isto é, cria na mente de uma pessoa um signo equivalente [...] um interpretante do primeiro signo" (PEIRCE, 1990, p. 46). Assim, todo signo deve representar algum objeto, mesmo sendo arbitrária sua condição, pois "todo signo tem, real ou virtualmente, um preceito de explicação segundo o qual ele deve ser entendido como espécie de emanação, por assim dizer, de seu Objeto" (PEIRCE, 1990, p. 47). Logo, se um signo for um símbolo, ele se corporifica em relação a um objeto. Lucia Santaella (1992, p. 112) afirma, a propósito do conceito de semiose, que essa corporificação se dá a partir de uma ideia suficientemente capaz de causar efeito em uma mente interpretadora. Esse processo descrito pela semioticista pode também se associar às analogias observadas por Octávio Paz. Mas, infelizmente para o poeta mexicano, Peirce não forneceu resposta suficiente para a questão da arbitrariedade na construção de sentido das relações de parentesco. Para Paz, essa questão é um mistério que remonta a origem, talvez, adâmica para o primeiro "não" da formação das interdições. Lévi-Strauss, segundo Paz, vale-se da linguística para buscar explicação para as relações de parentesco a partir da universalidade da proibição, uma vez que são análogas à linguagem. Segundo Paz, Lévi-Strauss "rechaça" qualquer explicação mítica, religiosa, filosófica para explicar a origem dessa questão, para ele:

todas las hipótesis con que se ha pretendido explicar el enigma del tabu del incesto, desde las teorías finalistas y eugenésicas hasta la de Freud. A propósito de este último señala que atribuir el origen de la prohibición al deseo por la madre y al asesinato del padre por los hijos, es una hipótesis que revela las obsesiones del hombre moderno pero que no corresponde a ninguna realidad histórica o antropológica. Es un "sueño simbólico": no es el origen sino la consecuencia de la prohibición. (1972, p. 21) (grifos meus). 
Paz verifica que essa regra convencionada fornece uma forma de significação que acaba por explicar a passagem da natureza à cultura. Em quase todas as obras de Lévi-Strauss, principalmente nas obras: O Cru e o Cozido (2004); El Totemismo en la Actualidad (1965); Antropologia Estrutural (2003), além das obras de Marcel Mauss, que retomaremos a seguir, e outras tantas citadas pelo autor, verifica-se essa passagem. Na obra O Cru e o Cozido (2004), como bem observa Paz, o leitor tem uma vertigem pela complexidade de signos tramados por Lévi-Strauss. Importa para essa sintaxe a presença do corpo feminino utilizado como moeda de troca ou potlach nas sociedades primitivas, aspecto que será retomado no decorrer desse ensaio. Todos os mitos sistematizados brilhantemente pelo antropólogo fundamentam a linguagem dos mitos indo-americanos. Um tema mítico fornece o conteúdo ou código corporificado com formas variáveis aproximativas e conteúdos diferentes. Essas diferenças são, muitas vezes, da ordem do corpo e constituem categorias sensoriais: paladar, olfato, audição, tato, visão. Muitos mitos explicam as interdições a partir da alimentação e da descoberta do fogo/corpo. O canibalismo é um exemplo disso: alimentos carnívoros, crus, moqueados (secados/assados) ou podres se associam ao ânus, ao excremento humano e à morte; e, em oposição binária, os alimentos vegetais, crus (frescos), podres ou cultivados associam-se à vida, à fertilização da terra, à vagina como o mito da mulher que cozinha mandioca na vagina na passagem da descoberta do alimento cozido. Geralmente, os mitos cozidos são híbridos devido à mistura de água, de fogo e de alimentos; ou do jaguar que rouba o fogo (simbólico) da mulher para explicar o nascimento do fogo. Antes os alimentos carnívoros eram secos ao sol e os vegetais eram comidos mesmo que apodrecidos. Nos dois tipos de canibalismo - vegetal ou animal - os alimentos apodrecidos esclarecem também as interdições:

A podridão vegetal conota, portanto, a atividade sexual normal (= conjugal) da mulher, a castidade normal (= pueril) do homem. E a podridão animal, a atividade sexual anormal (= estrupo) do homem e a castidade anormal (= conjugal) da mulher. (LÉVI-STRAUSS, 2004, p. 215).

Derivado desses eixos temáticos ou de outros, surgem às interdições constituídas a partir da relação binária: doença x saúde. Alimentos fedorentos/podres antecipam à morte, alimentos cheirosos/frescos (carne ou vegetal) são relacionados à saúde. Logo, alimentos que trazem doença (disenteria) acabam sendo proibidos. Em outras obras, como em El totemismo en la actualidad (1965), observa-se as interdições alimentícias associadas a alimentos considerados sagrados, a maioria vinculada a ritos mágicos. Outras associações proibitivas como chuvas, tempestades ou o aparecimento do arco-íris surgem em O Cru e o Cozido (2004) como resultado de alguma ação geradora de interdição, como índios que, em algumas sociedades indígenas, recebem como 
punição dos céus uma tempestade por cometer incesto. Outro aspecto interessantíssimo em Lévi-Strauss está em sinfonias do corpo nas quais imbricam questões estéticas. O corpo musical comparece nesta sinfonia sob duas grades: a primeira é fisiológica, natural, com ritmos orgânicos como a pulsação, o ritmo cardíaco, os odores ruidosos (flatos), o mastigar ruidoso como gerador de interdição, o riso que também explica a abertura para oralidade e para origem do fogo de cozinha; e a outra cultural numa escala de sons musicais cujos números e intervalos variam de cultura à cultura num sistema politonal e atonal. A música expõe o indivíduo com uma raiz fisiológica e os mitos, assim como a criação de instrumentos musicais, a raiz social e cultural. As posições: indivíduo e sociedade derivam do corpo, sobretudo da voz e do engajamento do corpo, ambos relatam a construção de interdições e, consequentemente, a ritualização dos gestos na construção de uma sintaxe estética:

o canto se diferencia da língua falada pelo fato de exigir a participação de todo corpo, mas rigorosamente disciplinado pelas regras de um estilo vocal [...] os mitos são frequentemente cantados, sua recitação é geralmente acompanhada de uma disciplina corporal: proibição de bocejar ou de ficar sentado, etc. (LÉVI-STRAUSS, 2004, p. 48) (grifo e verbo flexionado meus).

Todos esses signos traçados por Lévi-Strauss explicitam as interdições constituídas como textos culturais; em outros ainda, como El totemismo en la actualidad (1965) e Antropologia Estrutural (2003), ampliam esse aspecto a partir da relação entre homem, natureza e suas representações totêmicas, distinguidas por clãs nos quais grupos totêmicos não podem casar entre si. O mesmo se observa na clínica freudiana, em Totem e Tabu (2013).

Importa para essa discussão algumas diferenças estabelecidas em El totemismo en la actualidad entre totem e mana - elementos que mais a frente retomaremos com o potlach -, e suas implicações com Antropologia Estrutural quanto noção de significante flutuante em concomitância à concepção de sacrifício estabelecido por Marcel Mauss em Ensaio sobre a Dádiva (2013) e Sobre o Sacrifício (2013). A diferença entre totem e mana possibilita tangenciarmos aproximações com o corpo e suas interdições. A concepção de totem, embora esteja atrelada sócio-fisio-psicamente, no sentido de que há clãs-totêmicos que descendem de um grupo A ou B e, portanto, carregam no corpo características que lhe são inerentes ou internas, isto é, cada clã possui natureza, norma e comportamento distintivo em relação a outros clãs. Diferente da concepção de mana que, para Lévi-Strauss, circula fora do corpo, o "mana expresa una participación, una forma activa de acompañamiento que, por naturaleza, jamás está ligada de manera indisoluble a una cosa singular o a un ser humano" (LÉVI-STRAUSS, 1965, p. 54). Embora a distinção entre totem e mana aponte para o corpo-identidade (dentro), e corpo-social 
(fora), verifica-se, em outras obras, a presença do conceito de mana como uma energia que circula internamente ao corpo como um significante flutuante (MERQUIOR, 1975): que indicia a presença do inconsciente, energia-significante que possibilita ao xamã fazer a passagem do inconsciente ao consciente na cura. Essa passagem está presente (MERQUIOR, 1975; STRAUSS, 2003) nos conceitos de Split representation - imagens de pinturas primitivas que se desdobram - e, das pinturas do corpo dos índios Kadiwéu. Nela se resolve, além da passagem da natureza à cultura, a reintegração do corpo pela "rememoração do instante inaugural do fenômeno do sentido" (MERQUIOR, 1975, p. 19) reintegrando a significação - quando, antes, o signo estava em defasagem entre os polos de significante e significado - por meio de imagens: sínteses simbólicas de cenas experienciadas e depois sintetizadas no imaginário cultural, como nas pinturas e nas tatuagens dos Kadiwéu. A mediação desses dois estados, doença e saúde, expressa também o sacrifício totêmico. O significante flutuante percorre o corpo de dentro ou a psique e sai do corpo em conjunção de opostos de signos e de símbolos sagrados e profanos.

Segundo Marcel Mauss e Henri Hubert (2013), o sacrifício apresenta algumas distinções: o sacrifício-dadiva; o sacrifício-alimento (agrário ou carnívoro); sacrifício-contrato. Cada um deles constrói efeitos estéticos e sociais distintos e tipos de ritualizações que, em linhas gerais, "ligam” o sujeito ao ser sobrenatural com quem quer obter benefícios. O sacrifício originariamente é uma dádiva que, distanciado de seu modus primitivo/selvagem, pode ser definido como "um ato religioso que, mediante a consagração de uma vítima, modifica o estado da pessoa moral que o efetua ou de certos objetos pelos quais ela se interessa" (MAUSS; HUBERT, 2013, p. 21).

Independente do tipo de sacrifício, percebe-se uma mudança de estado que vai do "domínio comum" ao "domínio religioso" na passagem da morte ao renascimento ou da natureza à cultura. A palavra sai de estado de profanação enquanto signo comum e ganha carne imortal sagrada quando poema. Essa passagem ou mediação só ocorre quando vítima e divindade se tocam, transmutando desejos e interdições. O ato de "tocar" ou de "arder à palavra" - como explicita Octávio Paz em obras como O Arco e a Lira (2012) - está associado à presença do fogo como elemento capaz de transformar alquimicamente o corpo poético. Aspecto bastante estudado por Lévi-Strauss nos mitos que tratam da origem do fogo e que comparece em A Dupla Chama Amor e Erotismo (1994). A palavra só "arde" quando amor(e)tizada pela dupla chama: amor e erotismo. Esses componentes, uma vez aglutinados, tratam mais uma vez da passagem da natureza à cultura. $\mathrm{O}$ amor como uma construção e/ou convenção social, regulado pela lei, pelas interdições, e o erotismo pela liberdade do corpo. Essa mesma discussão aparece no ensaio Conjunções e Disjunções (1979), embora ampliada por uma sintaxe hindu/oriental. Nessa transição, percebe-se algo que Octávio Paz - nem mesmo Lévi-Strauss - não responde quanto à 
relação de interdição no fonema. Podemos inferir à luz da semiótica que o signo, nesta aliança, na construção de significação, abduz e aduz. Segundo Peirce (1990), as abduções estão - para abertura criativa - presentes nos textos mais inovadores como os quali-signos. Assim, poderíamos dizer que os sons que se abrem engajam corpo, voz e, consequentemente, a liberdade criadora ou a fertilização da palavra sem interdição, ao contrário da adução que fecha o corpo-voz na medida em que o sentido se dá como legi-signos, como lei que se associa aos sacrifícios e às interdições do corpo. Existem descrições feitas pela antropologia e pela clínica freudiana (FREUD, 2013), nas quais se isola (corpo/voz/silêncio) o homem ou a mulher em uma casa durante a passagem para adolescência, o que equivaleria à circuncisão. Outras analogias poderiam ser feitas a partir dessa relação entre aberto e fechado. Lévi-Strauss, em O Cru e o Cozido (2004), verifica as aberturas do corpo humano dentro de um sistema de "ingestão e dejeção", de canibalismo ou de vegetarianismo, nos quais se convocam os sentidos do corpo como metáforas da culinária da cultura.

De outra forma, poderíamos pensar a simultaneidade de abertura e fechamento de sons como polifonia ou semiose de textos em equilíbrio com as interdições e, em contrapartida, a monofonia em textos cuja interdição não se equilibra, polarizando o corpo em um sim ou em um não. Para Octávio Paz nada é somente isso ou aquilo - no sentido de sim ou de não polarizados -, os signos estão em conjunção de opostos na relação de corpo e de não corpo com a natureza e a cultura. Esse aspecto põe em questão o corpo fenomenológico na relação com tudo àquilo que toca e atrita em dialética com o outro. Marcos J. Müller em, Merlau-Ponty acerca da expressão (2001, p. 136), explicita que o ato de falar foi antes inaugurado pelos gestos do corpo na relação com os rumores dos sons que, uma vez integrados ao mundo, fornecem "uma extensão gestual, sonora e gráfica”. A fala, nesse sentido, estaria muito mais para parole, uma vez que resulta de um mundo gestual e simbólico que habita o corpo e, consequentemente, às interdições. Embora as teorias abordadas aqui: linguística, semiótica, fenomenologia pretendam dar conta das interdições a partir do corpo na relação com outro, na busca do primeiro "não" de Paz, ressaltamos que a noção de sujeito ou de indivíduo apontada anteriormente não existe nas descrições dos mitos de Lévi-Strauss, muito embora compreenda que o mito faça parte do sistema fonológico e da linguagem como texto. Mais do que isso, para Paz, a música e a poesia, sobretudo a música, não tem a mesma "clave" ou "código linguístico", pois não são linguísticos, embora prescindam da linguagem. Assim, música, poesia e mito transcendem à linguagem. Afirma o poeta mexicano em quase todas as obras ensaísticas que a palavra "tocada por la poesía, el lenguaje es más plenamente lenguaje y, simultáneamente, cesa de ser lenguaje: es poema" (PAZ, 1972, p. 55). 


\section{POTLACH UM EROS MEDIADOR: UM POEMA.}

A maior parte dos textos de Octávio Paz pensa o erotismo e a liberdade sexual a partir da mulher. Parte dessa discussão, que o poeta tomou para si, deve-se ao contexto histórico da emancipação da mulher no século XX, e, ao contexto mexicano que tem por característica a figura do feminino como símbolo presente nas poesias de Sor Juana Inês de la Cruz; na religião católica com Guadalupe; nos nativos Nahuas com a deusa Tonantzin; e do contato do poeta com a Índia e a deusa Parvati; parte se deve também a paixão pelo humano, pela arte em geral e pela política social, deve-se ainda a pessoa Octávio Paz que, por conceber a poesia ou a poética como um fenômeno feminino, era um homem metaforicamente feminino. Todas essas partes, talvez, expliquem o todo da poética de Octávio Paz e, de certa forma, elucidem a "intenção" de buscar na antropologia, na linguística e na semiótica elementos para compreender a liberação do corpo a partir das interdições, pondo em debate A Parte Maldita, de Georges Bataille.

Em Claude Lévi-Strauss o el Nuevo Festín de Esopo (1972), Paz observa dentro de um campo maior de discussão entre a linguística estrutural e a antropologia, apontados anteriormente, que um dos pontos fulcrais ou "iniciantes" das interdições do corpo advém das relações de troca ou do potlach constituído nas sociedades primitivas, afirma o poeta mexicano: "la interdicción no tiene otro objeto que permitir la circulación de mujeres y sentido es una contrapartida de la obligación de donar, estudiada por Mauss" (PAZ, 1972, p. 22). A referência feita pelo poeta nos remete - mais do que a mulher - ao próprio poema ou a palavra como um corpo feminino, haja vista a busca por uma sintaxe em o Festín de Esopo. Como se fosse um poema-mana no qual circula o fogo simbólico do feminino referenciado por Lévi-Strauss em O Cru e o Cozido, na descoberta do fogo ou pela doação de uma energia abdutiva criativa e autogerativa presente na poética e nos estudos semioticistas. Mas, Paz não compreende a mulher como elemento de semiotização sígnica: como símbolo do fogo criador, fertilizador ou do calor humano advindo das trocas feitas das sociedades arcaicas, ele a vê, no contexto de Lévi-Strauss com um valor moral, como um artifício. Afirma Paz:

La metamorfosis del sonido bruto en fonema se reproduce en la de la sexualidade animal en sistema de matrimónio; en ambos casos la mutación se debe a una operación dual (esto no, aquello sí) que selecciona y combina - signos verbales o mujeres. [...] Confieso que me cuesta trabajo aceptar que una norma inflexible y en la cual no es infundado ver la fuente de toda moral - fue el primer No que opuso el nombre el hombre a la naturaleza sea simplemente una regla de trânsito, un artifício destinado a facilitar el intercambio de mujeres [...] (PAZ, 1972, p. 21-23) (grifo meu). 
Paz não compreende como unidade de significação corpo e signo, na relação natureza e cultura, talvez por polarizar esses signos como "signos verbales" ou “mujeres", ou, talvez, seu olhar não seja arcaico o suficiente e, ambiguamente, observe a mulher como objeto valendo desde a origem no pregão das relações sociais e econômicas. Aspecto esse que poderia estar em sintonia com A Parte Maldita, de Georges Bataille, como uma explicação para as dualidades: proibição e doação; signo e mulheres, a mulher como potlach ou como mediadora de negócios. É difícil pensar essas questões éticas quando somos modernos e não selvagens.

O potlach, segundo Marcel Mauss, constitui-se como um sistema de dádivas contratuais estudadas na Polinésia e na Melanésia. Nos estudos sobre o potlach no Ensaio sobre a Dádiva (2013), observam-se variações de "tipos ${ }^{2}$ " de potlach, assim como há "tipos" distintos de sacrifícios apontados anteriormente. Há um "tipo" de potlach cujo contrato associa-se aos bens uterinos ou tonga, no qual o útero se configura como um canal pelo qual os filhos herdam os bens, assim como o mana de dádiva de nascimento, de alimento/fertilização/criação e de prestígio social, o mana doado deve retornar a origem nas trocas de reciprocidade. Assim ocorrem as trocas de circulação de bens de clã a clã. Dai que "as jovens filhas herdam, ao se casarem, os adornos, os talismãs que entram pela mulher na família recém-fundada, com a condição de reciprocidade; são, em suma, espécies de bens imóveis por destinação” (MAUSS, 2013, p. 21).

Para esse tipo de potlach não há rivalidade ou destruição, os bens circulam coletivamente a base de trocas. O potlach de destruição é decorrente das rivalidades entre tribos de clãs diferentes, portanto, esse tipo é por natureza masculino, posto que a mulher não participava de guerras, e, além disso, como afirma Lacan (LACAN, 1985; SILVA, 1995), a mulher "não é". Essa destruição, por outro lado, associa-se aos sacrifícios, quanto melhor e maior for o sacrifício, mais rápido se alcança o benefício. A competição se dá tendo como fundamento o valor, a qualidade da dádiva. Logo, a rivalidade, a ostentação e a busca pela grandeza estão presentes em todos os atos que, de outro modo, podem ser observados como jogo, como brinquedo: "aceitar uma das oferendas é mostrar que se está disposto a entrar no jogo, quando não a permanecer" (MAUSS, 2013, p. 50) nele. O mesmo ocorre nos jogos de afetos presentes no amor cortês (jouer du cour), nos jogos de sedução, nas fantasias e até nas relações sadomasoquistas observados por Paz em Um Mais Além Erótico: Sade (1999). As festas ou banquetes oferecidos no nascimento de um filho ou na dádiva de uma mulher como sinal de hospitalidade, no contexto primitivo, eram signos de inventividade, de criação abdutiva, o equivalente às festas carnavalizantes (BAKHTIN, 1981; 1993), nas quais todas as máscaras polifônicas são possíveis e igualmente prazerosas. 
É curioso observar, ainda, no potlach por destruição uma variação que perpassa a rivalidade e se fixa na morte. Nela os bens ou excedentes se perdem "como são perdidos na guerra, no jogo, na luta” (MAUSS, 2013, p. 66) em que não se doa ou retribui, mas se destrói totalmente, "queimam-se casas e milhares de mantas; os cobres mais caros são rompidos, atirados n'água, para esmagar, para “fazer calar” o rival” (MAUSS, 2013, p.66). Calar a voz é reter o corpo, é fechar o discurso, é acabar com o jogo, é construir interdição, uma vez que estabelece a proibição entre tribos ou clãs diferentes com a finalidade de delimitar fronteiras para assegurar a autoridade do chefe dentro de uma instância de poder. Essa mesma perda é análoga aos conceitos de Georges Bataille em A Parte Maldita (2013) acerca da noção de dispêndio, na qual não se comemora o nascimento/fertilidade/criação, mas a morte como perda suntuária. A Parte Maldita estrutura-se em dois tempos nos quais se discute as sociedades de consumação, como a dos astecas e as sociedades primitivas que fizeram uso do potlach na circulação de trocas; e da sociedade de empreendimento militar ou industrial na qual convivem tipos de excessos ou dispêndios improdutivos que, como um mana poderoso, percorre a religião, a economia capitalista que tenta se livrar do excedente "doando" a monarquia, a arte, a ciência, a filosofia etc. Esses dois momentos expressam, em linhas gerais, que tudo para Bataille é um grande potlach de morte. Dois momentos cuja "utilidade econômica/valorativa" poderia até sugerir trocas de reciprocidade, mas que se subordina à morte, à violência, à transgressão das interdições para obter prazer, o que poderíamos até pensar em dois "tipos" de potlach: um por reciprocidade e outro por perda. Mas, até mesmo o potlach por reciprocidade de Bataille perpassa a destruição das interdições e, consequentemente, do encontro com o real para se chegar ao êxtase/renascimento, assim como os instintos bataillianos que precisam rasgar as repressões constituídas para paradoxalmente se afirmar como um selvagem. Logo, há apenas uma única tônica em A Parte Maldita, o potlach por destruição como perda suntuária.

Essas questões se constituem como um problema de interpretação para Octávio Paz, uma vez que Mauss não vê o potlach somente como destruição ou como um dispêndio de energia "maldita", mas como troca em circulação de bens em semiose de signos e símbolos tanto para vida quanto para a morte, uma vez que se constitui como passagem, como um significante flutuante a percorrer a música e a poesia, os sons, os signos e os corpos. Além disso, é importante situar, nesse embate, as considerações finais de Marcel Mauss no Ensaio sobre a Dádiva a despeito das sociedades de trocas, nas quais enfatiza o erro de se pensar a economia moderna à luz das trocas primitivas, por certo, assevera Mauss, existem ecos simbólicos que estão fixados na sociedade, assim como há uma forte vinculação jurídica nas relações de propriedade do potlach, mas todos se distanciam da realidade das sociedades arcaicas. Nesse sentido, não seria leviano pensar a 
inventividade poética de Bataille (seus romances) como uma temática com variações do mesmo, uma vez que "vende" a arte como dispêndio de energia erotizada e transgressiva que, no entanto, apresenta quase sempre a mesma estrutura, o mesmo "ô(â)nus" como moeda de troca da "mais valia" social.

Para Octavio Paz, poesia, música e arte não têm preço, são dádivas que nutrem o corpo, por isso, são viscerais; por isso, são úteis enquanto moeda de troca. Seu erotismo é um corpo-signo-texto do imaginário, suas transgressões são da ordem da invenção, da abdução fértil. Em todos seus textos, direta ou indiretamente, enfatiza-se o potlach como uma passagem da natureza (sexualidade) à cultura (erotismo). O corpo erotizado da palavra vincula-se à cultura, à representação estética e, consequentemente, às interdições sociais. O amor associa-se à aliança/casamento, o erotismo é metáfora de liberdade sexual e ambos são Eros mediados por potlach com ética. Assim como Bataille, Octávio Paz verifica que é preciso transgredir até mesmo para sublimar, na palavra, a matéria sexual. Mas com uma diferença: a transgressão para Paz só pode existir quando se conjuga técnica e experimentalismo, tradição e ruptura. O Kama Sutra, por exemplo, foi constituído como um manual estético/eratológico (como lei simbólica), dentro da cultura Hindu, pensando no corpo-comunicacional pelo encaixe/montagem dos corpos em conjunção de opostos: masculino e feminino, sagrado e profano, sim e não. Algo que Paz pretendeu no poema Blanco, signo do oriente extremamente corpóreo e feminino. Esse tipo de transgressão só seria possível num contexto oriental tântrico, no qual o erotismo é o caminho para o Kundalini ${ }^{3}$, o equivalente à vida, a mediação de um corpo-texto-erotizado, ao contrário de Bataille, que associa essa transgressão à morte, ao êxtase como potlach de destruição.

Por outro lado, as transgressões poéticas e a ensaística paziana estão em consonância com o desejo de imprimir à palavra um gesto latino. Gesto cuja tônica se prende a um contexto de aculturação e de deslocamento de investimento associado à ordem ou ao caos católico em confluência com a natividade mixteca. Nela deslocam-se os sacrifícios, os signos, assim como a forma de simbolizar o desejo. Paz desejava para o povo latino um dispêndio erotizado/estético/ econômico que não necessitasse da morte de seu povo para se chegar ao êxtase de Madre Tereza. Desejava, sob o signo do feminino, um corpo-texto-erotizado associado à pulsão de vida. Ao contrário de Georges Bataille que fundou a morte como filosofia e estética ou a parte maldita: zona erógena constituída na intimidade instintiva de corpos, espaço que, para Bataille, só pode existir em reciprocidade, mas cujo excesso se apresenta como uma espécie de "mais valia" dos desejos e se fixa, a partir da interpretação das ideias de M. Mauss, na troca das perdas suntuárias, do dispêndio de energia improdutivo das relações econômicas e, consequentemente, dos investimentos corpóreos erotizados na arte em geral. 


\section{NOTAS}

1 Potlach significa essencialmente "nutrir", “consumir” (MAUSS, 2013, p.15).

2 A classificação de "tipos" de potlach não consta em Marcel Mauss, trata-se de uma interpretação feita por mim, uma vez que existem variações. Não há potlach único nem mesmo juridicamente.

3 Kundalini apresenta como símbolo a serpente adormecida. Uma vez despertado o chakra genital, libera-se a inteligência criativa, a iluminação interior. Segundo J. Campbell (1997a; 1997b), no Hinduísmo, seu despertar poderoso está associado à deusa, à Mãe Divina e, consecuentemente, à vida.

\section{REFERÊNCIAS}

BAKHTIN, Mikhail. Problemas da poética de Dostoiévski. RJ: Forense Universitário, 1981.

BAKHTIN, Mikhail. Questões de literatura e de estética. SP: Unesp/HUCITEC, 1993.

BATAILLE, Georges. A parte maldita, precedida de "A noção de dispêndio". Belo Horizonte: Autêntica, 2013.

BATAILLE, Georges. O Erotismo. SP: Arx, 2004.

CAMPBELL, Joseph. O Herói de Mil Faces. SP: Cultrix, 1997a.

CAMPBELL, Joseph. As Transformações do Mito através do Tempo. SP: Cultrix, 1997b.

FÁVERO, Leonor Lopes; KOCH, Ingedore G.Villaça. Linguistica textual: uma introdução. SP: Cortez, 1988.

FREUD, Sigmund. O mal estar da Civilização. SP: Penguin/Cia das Letras, 2013b.

FREUD, Sigmund. Totem e Tabu. São Paulo: Penguin/Cia das Letras, 2013.

GRUZINSKI, Serge. A colonização do imaginário: sociedades indígenas e ocidentalização no México espanhol. SP: CIA das Letras, 2003.

LACAN, Jacques. O Seminário - livro 7 - a ética da psicanálise. RJ: Zahar, 1986.

LACAN, Jacques. O Seminário - livro 11 - os quarto conceitos fundamentais da psicanálise. RJ: Zahar, 1985.

LAFAYE, Jacques. Quetzalcóalt y Guadalupe: la formación de la consciência nacional em México. México, 1992.

LÉVI-STRAUSS, Claude. Antropologia estrutural. RJ: Tempo Brasileiro, 2003.

LÉVI-STRAUSS, Claude. EI Totemismo em la actualidad. México/Buenos Aires: Fondo de Cultura Economica, 1965.

LÉVI-STRAUSS, Claude. O Cru e o cozido. SP: Cosac Naify, 2004. 
MACIEL, Maria Esther. A Palavra inquieta: homenagem a Octavio Paz. Belo Horizonte: Autêntica/Memorial da América latina, 1999.

MAUSS, Marcel. Ensaio sobre a Dádiva: forma e razão da troca nas sociedades arcaicas. São Paulo: Cosac Naify, 2013.

MAUSS, Marcel; HUBERT, Henri. Sobre o sacrifício. São Paulo: Cosac Naify, 2013.

MERQUIOR, José Guilherme. A estética de Lévi-Strauss. RJ: Tempo Brasileiro/Universidade DF, 1975.

MÜLLER, Marcos José. Merleau-Ponty acerca da expressão. Porto Alegre: EDIPUCRS, 2001.

PAZ, Octávio. A dupla chama: amor e erotismo. São Paulo: Siciliano, 2001.

PAZ, Octávio. Claude Lévi-Strauss: o el nuevo festín de Esopo. México, 1972.

PAZ, Octávio. Conjunções e Disjunções. SP: Perspectiva, 1979.

PAZ, Octávio. O Arco e a Lira. São Paulo: Cosac Naify, 2012.

PAZ, Octávio. O Ogro Filantrópico: História e Política. RJ: Guanabara, 1989.

PAZ, Octávio. O Vislumbre da Índia: um diálogo com a condição Humana. SP: Mandarim, 1997.

PAZ, Octavio. Los Hijos del Limo. Barcelona: Talleres Gráficos Hurope, 1990.

PAZ, Octávio. Signos em Rotação. São Paulo: Perspectiva, 1990.

PAZ, Octávio. Sor Juana Inês de la Cruz: Las Trampas de la Fe. México: Fondo de Cultura Economica, 1985.

PAZ, Octávio. Um mais além erótico: Sade. São Paulo: Mandarim, 1999.

PAZ, Octávio; CAMPOS, Haroldo. Transblanco: em torno a Blanco de Octavio Paz. RJ: Guanabara, 1986.

PEIRCE, Charles S. Semiótica. SP: Perspectiva, 1990.

SANDRONI, Paulo (Org.). Novíssimo dicionário de economia. SP: Best Seller, 2004.

SANTAELLA, Lucia. A assinatura das coisas: Peirce e a Literatura. RJ: Imago, 1992.

SANTAELLA, Lucia. Teoria geral dos signos: semiose e autogeração. SP: Ática, 1995.

SANTAELLA, Lucia. Texto. In: JOBIM, José Luis (org). Palavras da Crítica. RJ: Imago, 1992.

SILVA, Maria Escolástica Álvares. A Mulher não existe. In: Oscar Cesarotto. (Org.). Ideias de Lacan. São Paulo: Iluminuras, 1995. 